Brit. J. Ophthal. (1960) 44, 562.

\title{
SEGMENTAL LESIONS OF THE RETINAL ARTERIES*
}

\author{
BY
}

\author{
R. K. BLACH \\ London
}

FEW cases with segmental lesions of the retinal arteries have been described. Suganuma (1927) reported a case with retinal perivasculitis, giving the pathological findings in an enucleated eye. Kyrieleis (1933) gave the first description of periarteritis retinae occurring in uveitis. Muncaster and Allen (1939), Thompson (1952), and Griffin and Bodian (1959) described five further cases. Another three cases are described below.

\section{Case Reports}

Case 1, a Jamaican Negress born in 1930, suffers from uveitis. In 1954 she noticed episodes of "glaring vision" lasting a few minutes in the right eye; 3 years later the vision in that eye became hazy, and she was found to have an old thrombosis of the right superior temporal vein with patches of old choroiditis at the posterior pole and in the upper temporal region. The visual acuity in the right eye was $6 / 9$, and in the left eye 6/6. In February, 1959, the visual acuity of the right eye deteriorated further. Her general health is good. She had an appendicectomy at the age of 16 years, has had three abortions after 3 months of pregnancy for no established reason, and suffers indefinite back pain. She is sensitive to eggs, ackee (a Jamaican fruit), sulphadimidine, and para-aminosalicylic acid. Taking the two latter substances caused her to become apprehensive and to develop a high intermittent fever, a macular skin rash, and a hazy vitreous with deterioration of vision.

Examination (February, 1959).-Both eyes showed aqueous flare and cells, and there was hazy vitreous containing floaters. The right fundus showed marked sheathing of the upper temporal vein and a black pigmented spot near the macula. Visual acuity in the right eye was 6/36 and in the left 6/9. As the vitreous began to clear, small, discrete, refractile white dots were seen on the larger arteries of both fundi (Fig. 1, opposite).

\section{Laboratory Investigations:}

Blood: Haemoglobin 100 per cent.; leucocyte count 4,200 (neutrophils 72 per cent., eosinophils 2 per cent., lymphocytes 22 per cent., monocytes 4 per cent.).

No lupus erythematosus cells were found, and anaerobic preparations for sickle cells were negative.

Erythrocyte sedimentation rate: $18 \mathrm{~mm}$. in the first hour.

Urine: Normal.

$X$-rays: Sinuses and chest normal. 


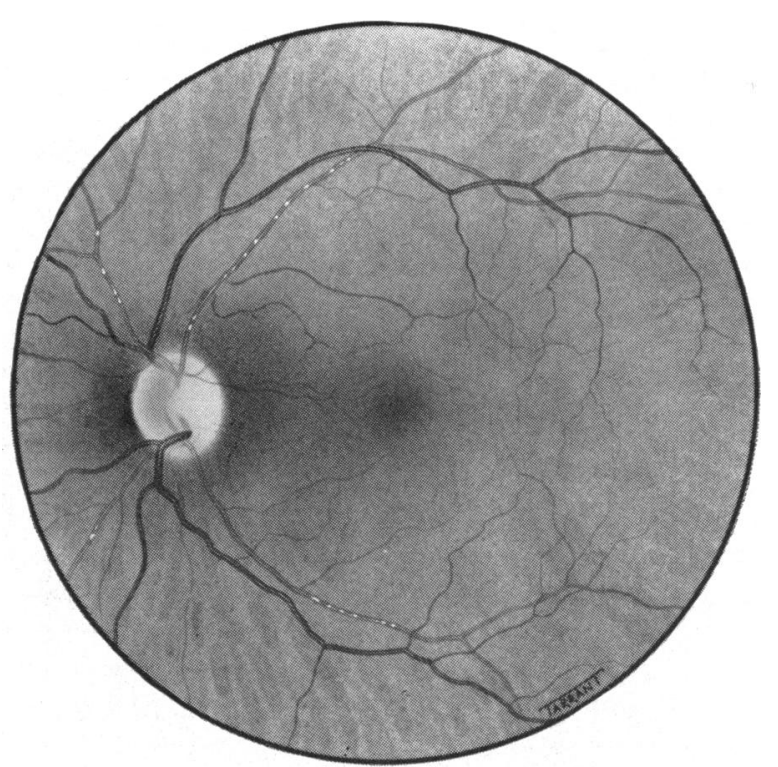

Fig. 1.-Case 1, left fundus.

Wassermann reaction, Kahn test, gonococcal complement-fixation test, and brucellosis agglutination test: Negative.

Toxoplasmosis dye test: Positive $1: 7$; complement-fixation test: Negative.

Mantoux reaction: Positive to $1: 10,000$.

Therapy.-She was treated on a sanatorium regime for 3 months, and was given prednisolone tablets $5 \mathrm{mg}$. three times daily, potassium chloride tablets $7 \frac{1}{2}$ gr. once daily, hydrocortisone drops 2-hourly, Daraprim tablets $25 \mathrm{mg}$. once daily, sulphadimidine tablets $0.5 \mathrm{~g}$. three times daily, para-aminosalicylic acid tablets $5 \mathrm{~g}$. twice daily, and isoniazid tablets $100 \mathrm{mg}$. twice daily.

The isoniazid, para-aminosalicylic acid, and sulphadimidine were stopped because of her sensitivity to the two latter substances.

The media have now cleared, and the visual acuity is $6 / 9$ in the right eye and $6 / 6$ in the left eye with glasses. The white spots have remained on the retinal arteries.

Case 2, a Negro from Sierra Leone born in 1915, suffers from uveitis. At the age of 14 years both his eyes became painful and the vision was blurred. There was recurrent inflammation of both eyes until 1950, by which time the right eye had become blind. In 1958 the visual acuity in the left eye was again reduced. He suffers from pityriasis versicolor of the trunk and arms, and also has a chronic swelling of the left ankle and some carious teeth.

Ophthalmological Examination (November, 1958).--The right eye was divergent. There was an aqueous flare, and a complicated cataract prevented any view of the vitreous and fundus. The ocular tension was soft and the visual acuity was perception of light with poor projection.

In the left eye the cornea showed some keratic precipitates, and there was aqueous flare and cells. The lens had some pigment on its anterior capsule but the iris was free. The vitreous was hazy and contained large black floaters. White, atrophic lesions with 
peripheral pigment were present in the fundus. The visual acuity was $6 / 36$. When the vitreous had partially cleared, small, white, refractile particles were seen on the posterior face of the vitreous, and many of these were arranged along the course of the retinal arteries. With further clearing the refractile dots seemed to become a little smaller, and those that remained were chiefly on the course of the arteries (Fig. 2).

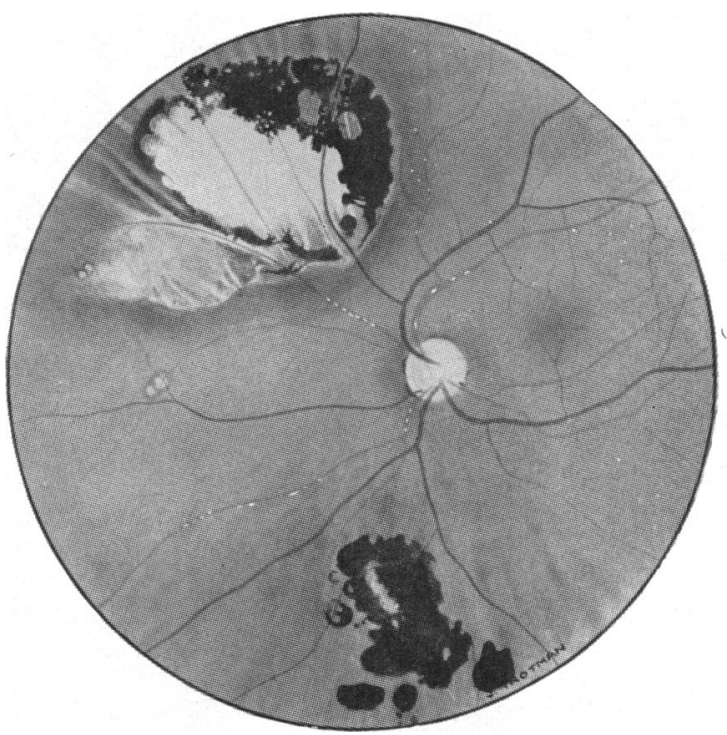

FIG. 2.-Case 2, left fundus.

Special investigations revealed no evidence of tropical disease (onchocerciasis and filariasis being especially excluded), no evidence of genital infection, and no general evidence of periarteritis nodosa.

\section{Laboratory Investigations:}

Blood: Haemoglobin 100 per cent.; leucocyte count 1,200 (neutrophils 63 per cent., lymphocytes 34 per cent., monocytes 3 per cent.).

Erythrocyte sedimentation rate: $4 \mathrm{~mm}$. in the first hour.

Urine: Normal.

Wassermann reaction, Kahn test, gonococcal complement-fixation test, and brucellosis agglutination tests: Negative.

Toxoplasmosis dye test: Positive 1:60; complement-fixation test: Negative.

Mantoux reaction: Positive to $1: 10,000$.

$X$-rays: Sinuses, hands, feet, and chest normal (apart from some cardiac enlargement which was not confirmed clinically).

Therapy.-He was treated on a sanatorium regime for 5 months and was given prednisolone tablets $5 \mathrm{mg}$. three times daily, potassium chloride tablets $7 \frac{1}{2}$ gr. once daily, hydrocortisone drops 2-hrly., Daraprim tablets $25 \mathrm{mg}$. once daily, sulphadimidine tablets $0.5 \mathrm{~g}$. three times daily, para-aminosalicylic acid tablets $5 \mathrm{~g}$. three times daily, isoniazid tablets $50 \mathrm{mg}$. three times daily, and atropine drops 1 per cent. to the left eye.

The media of the left eye cleared and the old choroidal lesions became more clearly defined. The visual acuity has improved to $6 / 12$, but the lesions on the retinal arteries have remained. 
Case 3, an Englishman born in 1917, suffers from uveitis. On May 12, 1955, a jet of compressed air hit his right eye and 3 days later that eye became painful and its vision misty. He stated that he had recently been overworked because of business difficulties. He had had a cutaneous patch of lupus erythematosus for 9 years but there had been no evidence of systemic involvement.

Examination.-The right eye showed corneal oedema, keratic precipitates, aqueous flare and cells, Koeppe nodules, posterior vitreous haze, a patch of uveitis superotemporally, and discrete white patches on the retinal arteries (Fig. 3).

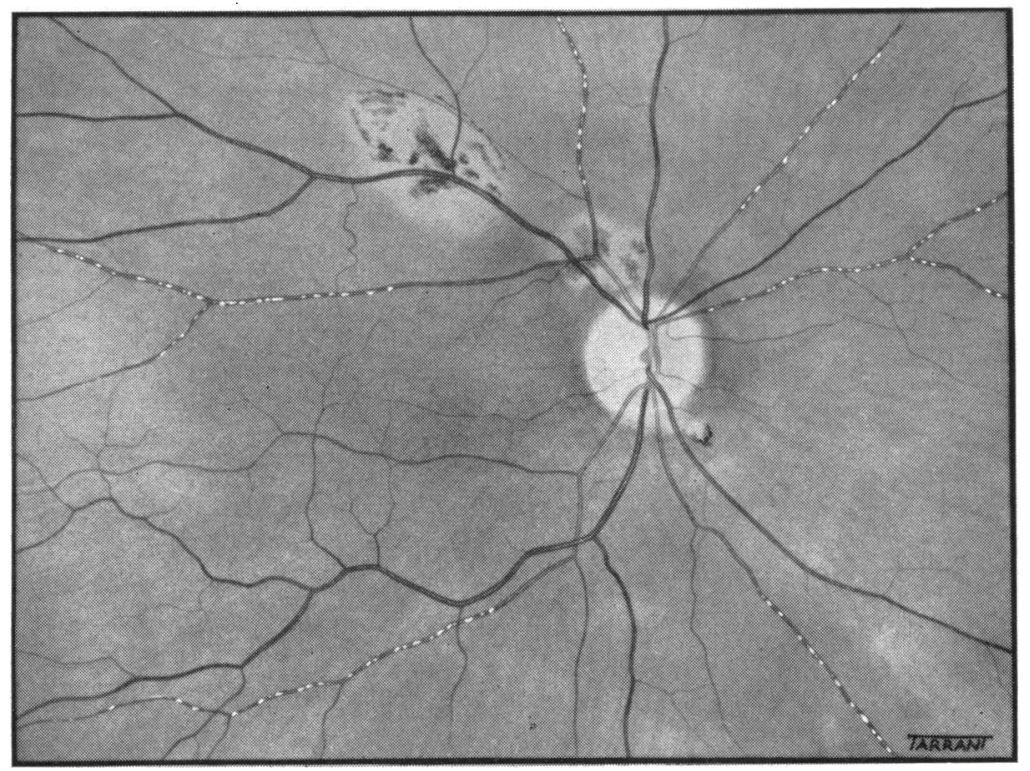

FIG. 3.-Case 3, right fundus.

The left eye was normal. The visual acuity in the right eye was $6 / 9$ ptly and in the left $6 / 5$.

Laboratory Investigations:

Blood: Haemoglobin 117 per cent.; leucocyte count 7,700 (neutrophils 64 per cent., eosinophils 1 per cent., lymphocytes 31 per cent., monocytes 4 per cent.).

Erythrocyte sedimentation rate: $5 \mathrm{~mm}$. in the first hour.

Urine: Normal.

Wassermann reaction, Kahn test, gonococcal complement-fixation test, and brucellosis agglutination tests: Negative.

Toxoplasmosis dye test: Positive $1: 22$; complement-fixation test: Positive $1: 8$.

Mantoux reaction: Positive $1: 10,000$.

$X$-rays: Chest normal.

Therapy.-Cortisone drops and atropine drops. He failed to attend after July 19, 1955.

No eyes from these cases have become available for pathological examination.

\section{Discussion}

Suganuma (1927) reported a case of segmental perivasculitis with vitreous haemorrhage, retinal haemorrhages and exudates, and retinal separation. 
He described the pathology of an enucleated eye as typical of tuberculosis. The retinal arteries in some areas were pushed forward in the nerve fibre layer by perivascular accumulations of epithelioid cells. There was cellular infiltration of the arterial walls but the intima was not affected, and a microphotograph of an arterial lesion is compatible with that of granulomatous arteritis. Pathologically this eye resembles that of a case of sarcoidosis reported by Levitt (1941). This case did, however, show clinical differences from the other cases with segmental retinal periarteritis chiefly in that it presented as a vitreous haemorrhage rather than a uveitis. It is not possible therefore to apply the findings in this case-a segmental granulomatous arteritis-to the other cases mentioned in this article.

In certain cases of uveitis fine white dots are seen on the posterior vitreous face. They can usually be diagnosed ophthalmoscopically by parallax in relation to the retinal vessels, and often they appear to lie over or on the retinal arteries. They have been illustrated and described by Goldmann (1954). In one of his illustrations a deposit appears to lie on a retinal artery while the other lesions are on the slightly detached posterior vitreous face. Case 2 in the present series showed similar lesions.

The aetiology of these arterial lesions is a matter for speculation. They appear to be related to uveitis in general and to the deposits in the posterior vitreous in particular. They outlast the deposits on the posterior vitreous face but may disappear when the uveitis has become inactive. It is not known whether these lesions are deposits on the arterial wall, consisting of cells or some extra-cellular substance, or whether they are inflammatory foci of the artery itself. Speculation is likely to be relatively valueless until pathological material is available.

\section{Summary}

Three cases of uveitis showing segmental lesions of the retinal arteries are described. The aetiology of these lesions is discussed in the light of these and previously reported cases.

I wish to thank Mr. A. G. Cross for his encouragement and help, Prof. Norman Ashton for his advice, and Mr. F. W. Law and Mr. N. H. L. Ridley for permission to publish their cases.

\section{REFERENCES}

Goldmann, H. (1954). “Two Lectures on Biomicroscopy of the Eye”, p. 24, and Fig. 24 (p. 47). Rösch, Vogt, and Co., Berne.

GrifFIN, A. O.., and Bodian, M. (1959). Amer. J. Ophthal., 47, 544.

KYRIELEIS, W. (1933). Arch. Augenheilk., 107, 182.

LeVITT, J. M. (1941). Arch. Ophthal. (Chicago), 26, 358.

MUNCASTER, S. B., and Allen, H. E. (1939). Ibid., 21, 509.

Suganuma, S. (1927). v. Graefes Arch. Ophthal., 118, 443.

ThOMPSON, A. M. WRIGHT (1952). Brit. J. Ophthal., 36, 268. 